\title{
AS LITERATURAS AFRICANAS EM TEMPOS PÓS-UTÓPICOS*
}

\author{
Eliana Lourenço de Lima Reis
}

UFMG

\begin{abstract}
RESUMO
Décadas depois do processo de descolonização, os escritores africanos contemporâneos procuram fazer uma crítica aos rumos tomados pelas novas nações e oferecer respostas para o fim das utopias revolucionárias. Em A montanha da água lilás, Pepetela rememora o passado recente de Angola em forma de fábula para criticar os erros cometidos e reiterar sua confiança no sonho socialista remodelado.
\end{abstract}

\footnotetext{
PALAVRAS-CHAVE

utopia, literatura africana, Pepetela.
}

Dreams

Hold fast to dreams For if dreams die Life is a broken-winged bird That cannot fly.

Hold fast to dreams For when dreams go Life is a barren field Frozen with snow. Langston Hughes

Os escritores africanos exerceram um papel importante nas lutas pela descolonização, através da criação de narrativas de fundação no campo da ficção ou da crítica literária e cultural $^{1}$ (como Wole Soyinka e Chinua Achebe, na Nigéria), ou ao conciliar a atividade literária com a participação pessoal na luta armada ou na vida política dos diversos países do continente, como Ñgugi wa Thiong'o (no Quênia) e o angolano Pepetela.

$\mathrm{Na}$ África lusófona, a obra de Pepetela (Artur Pestana dos Santos) pode ser vista como paradigmática da produção literária africana das últimas décadas do século XX,

\footnotetext{
* Este trabalho é parte de minha pesquisa de pós-doutoramento, realizado em 2001-2, com bolsa da CAPES. Esta etapa da pesquisa foi orientada pela Profa. Laura Padilha (UFF).

${ }^{1}$ Para uma discussão detalhada da criação das literaturas nacionais após a descolonização, ver, entre outros, ASHCROFt et al. The Empire Writes Back; BOEHMER. Colonial and Postcolonial Literature; OWOMOYELA, A History of Twentieth-Century AfricanLiteratures.
} 
sobretudo quando se leva em conta a estreita relação que estabelece entre a política e a escrita não só durante as lutas pela independência mas também durante o processo de constituição da nação. A trajetória de Pepetela assemelha-se àquela percorrida por vários de seus contemporâneos: o encontro com outros estudantes africanos na Europa e o impacto das idéias anticolonialistas; a formação universitária (no caso de Pepetela, o curso de Sociologia na Argélia recém-libertada da França); a articulação política pela independência; a participação na guerrilha e, em seguida, no governo; a desilusão progressiva com os rumos tomados pelos novos governantes e o afastamento gradual do poder. Permanece, no entanto, a confiança obstinada na força da escrita.

No âmbito da literatura, ocorreu na África pós-independência um processo semelhante ao que se verificou na América Latina no século XIX e que foi discutido por Doris Sommer em Foundational Fictions, isto é, o papel importante assumido pelo romance na constituição da nacionalidade (nation-ness ${ }^{2}$ ), por apresentar alegorias da nação baseadas sobretudo no "romance irresistível" que uniria os descendentes dos europeus e os diversos grupos étnicos africanos.

$\mathrm{Na}$ África de Pepetela, como se sabe, o sentimento de nation-ness acha-se indissoluvelmente ligado ao pensamento utópico e revolucionário que marcou a década de 60 e que pode ser também observado na maioria de seus contemporâneos, que, em geral, propõem uma literatura engajada politicamente. Em Angola, é um poeta que assume o poder após a independência: Agostinho Neto, autor do volume intitulado emblematicamente Sagrada esperança. Escrever, então, é escrever a utopia, um projeto de nação imaginada, sonhada através de alegorias nacionais - confirmando, ao menos neste caso, a controvertida afirmação de Fredric Jameson, de que toda literatura produzida no Terceiro Mundo constituiria uma alegoria da nação ${ }^{3}$. Nos romances de Pepetela, o processo alegórico serve a um propósito duplo, visando não apenas a apresentar a direção a ser tomada pelo país mas também a criticar os desvios de uma utopia concebida a partir dos ideais iluministas de liberdade, igualdade, fraternidade. Assim, o registro da memória recente ou a reescrita do mito enquadram-se no projeto político e social de escritores que cumprem uma função ao mesmo tempo nova e muito antiga. Por um lado, cabe-lhes indicar novas bases morais e políticas para uma sociedade organizada nos moldes modernos, ou seja, inspirada nos princípios da democracia e da igualdade, no valor do homem comum e não na estrutura hierarquizada em que se baseavam tanto a sociedade colonial como as sociedades tradicionais. Por outro lado, o artista é chamado a produzir obras que cumpram os mesmos objetivos que lhes eram atribuídos nas sociedades tradicionais, ou seja, além de divertir e educar, também preservar os costumes e a cultura. Tal posição está fadada a uma tensão difícil de ser negociada, pois o intelectual que defende um projeto modernizador (mesmo que este valorize a preservação da tradição) não mais aceita apenas servir de porta-voz ao poder (mesmo que este esteja agora nas mãos das elites locais, que ele apoiou). Assim, as narrativas de fundação servem para criar uma comunidade imaginada e, ao mesmo tempo, para criticá-la, buscando corrigir seus desvios de rota.

\footnotetext{
${ }^{2} \mathrm{O}$ termo nation-ness, cunhado por Benedict Anderson, não possui equivalente em português.

${ }^{3}$ JAMESON. Third World Literature in the Era of Multinational Capitalism.
} 
Como observa o próprio Pepetela, sua obra, "em termos políticos, obedece a uma espécie de programa mínimo," ${ }^{4}$ que foi apresentado em Muana Puó (1978), em que se narra a história de amor entre indivíduos de grupos sociais diferentes e que, apesar do desfecho infeliz, aponta para o sonho que permanece: o "romance irresistível" que uniria descendentes dos colonos portugueses e os membros das várias etnias africanas em um projeto comum. É a partir da consciência desse projeto, bem como da dificuldade de colocálo em prática, que Pepetela se volta para o passado recente em Mayombe (escrito em 1971, mas publicado em 1980) e em A geração da utopia (1992), romances de abordagem realista sobre as guerras de independência em Angola. Apesar de ter participado delas ativamente tanto como articulador político quanto como guerrilheiro, desde o início Pepetela demonstra um afastamento crítico surpreendente, principalmente quando se considera que Mayombe começou a ser escrito ainda durante o período de luta. Ao contrário da maior parte da literatura produzida na época, de caráter marcadamente épico (nos moldes da poesia de Agostinho Neto), esse romance não apresenta os guerrilheiros como heróis, mas como seres humanos em seus momentos de coragem e fraqueza, de companheirismo e de dissensões, de discussão acerca do futuro e de dúvidas quanto a ele. Ao optar por narrar os acontecimentos do ponto de vista dos diversos personagens, o romance evita lançar luz sobre apenas um protagonista - embora um deles, o comandante Sem Medo, desponte como a figura do herói, mas um herói que, por morrer ao final da narrativa, não se vê obrigado a enfrentar as dificuldades e decepções dos tempos pós-independência. A geração da utopia, como indica o próprio título, completa o registro da memória recente de Angola e do desejo de construir uma nação em novos moldes. Legítimo representante da geração criada durante a década de 60 , Pepetela mantém em sua escrita os ideais revolucionários da época de sua formação como sociólogo na Argélia, durante os movimentos de descolonização na África e, sobretudo, em Angola. No entanto, esses ideais passaram pelo crivo da realidade na etapa pós-revolucionária, notória pelas lutas sangrentas e intermináveis. Esse confronto deixa sua marca na obra de Pepetela, que demonstra uma firme adesão à utopia, acompanhada, porém, do sentimento de que o projeto nacional necessita de revisão permanente.

Isso faz com que o espírito de revolta, que se colocava como uma noção tão central à formação do escritor, tenha de ser reformulado, adequando-se ao presente. De fato, tal reformulação pode ser observada na escrita de outros representantes da mesma geração, tanto na África quanto na Europa, como, por exemplo, Julia Kristeva. Em seus comentários elaborados à época da comemoração dos 30 anos da chamada revolução de maio de 68 na França, Kristeva parte de uma frase de Camus (que, por sua vez, toma-a de Descartes): "Eu me revolto, portanto nós existimos"; a expressão é em seguida traduzida em termos mais apropriados para a época atual: "Eu me revolto, portanto nós viremos a ser." ${ }^{5}$ Para a autora, "a revolta moderna toma a forma da prova, do tatear, da aprendizagem baseada no tato, do ajuste analógico e paciente, da rede indecidível..." ${ }^{6}$ Daí que "pensar é se revoltar,

\footnotetext{
${ }^{4}$ VENÂNCIO. Literatura e poder na África lusófona, p. 98.

${ }^{5}$ KRISTEVA. Contre la dépression nationale, p. 47.

${ }^{6}$ KRISTEVA. Contre la dépression nationale, p. 66.
} 
estar no movimento do sentido e não da rua", o que faz com que a transformação do intelectual em "dirigente" acabe por se tornar uma atitude equivocada. A revolta do intelectual deveria, então, estar relacionada ao sentido etimológico do termo: "um retorno, uma retomada do passado visando a um deslocamento, uma interrogação, um sarcasmo, contestação, insolência, ruptura." Para Kristeva, revoltar-se associa-se, então, ao verbo latino revolvere, bem como à idéia de revolução - vista como o ato de voltar no tempo e para dentro de si -, à lembrança como anamnese, e, portanto, à reconstituição da memória, à interpretação do passado e do presente, à revisão dos valores - tudo isso através da ficção e da arte. ${ }^{8}$

Se relermos Pepetela à luz das formulações de Julia Kristeva, poderíamos dizer que, para o autor, a revolta seria uma forma de se manter viva a utopia da revolução, tomada no sentido de uma busca não só de liberdade, mas também da felicidade para todos. Mais, ainda: narrar a utopia sob diversos ângulos, como ele tem feito, significa questioná-la seguidamente como forma de recriá-la. Talvez seja a isso que se refere o final de Muana Puó:

"E [ela] compreendeu, trôpega, arrastando-se, que ele fora o sonho feito para se perder. Eternamente procuraria (...) certa de não o encontrar. Mas essa busca dava-lhe ainda força para viver. E criar vida." 9

"What happens to a dream deferred?", perguntava Langston Hughes na época da segregação racial nos Estados Unidos. As possibilidades seriam várias e o poema as apresenta em forma de perguntas de teor variado: "Does it dry up/ like a raisin in the sun/ Or fester like a sore -/ And then run?" O final do poema deixa no ar a possibilidade de duas atitudes extremas e opostas: "Maybe it just sags/ like a heavy load. / Or does it explode?"10 (A pergunta final ganha ênfase tanto por sua localização em uma linha separada como pelo uso de itálicos.) De modo análogo, pode-se perguntar: o que acontecerá ao sonho, sempre adiado, do povo angolano? Na verdade, é a essa pergunta que Pepetela retorna continuadamente, como se sugerisse, parafraseando as palavras de Kristeva: Eu me revolto, portanto nós nos voltamos para nós mesmos e para nossa história; nós olhamos para o passado a fim de preparar o futuro - mesmo quando se põe em dúvida a eficácia das narrativas, como parece sugerir o final da maioria de seus textos.

O que aconteceu com aqueles que Pepetela descreve como "a geração da utopia"? Será que deixaram herdeiros ou sucessores? Como evitar que o sonho, sempre adiado, desapareça ao se desmoronar ou mesmo ao explodir, como alerta Hughes? Em outras palavras, é preciso criar meios de manter os sonhos na literatura contemporânea, que Haroldo de Campos chamou de "pós-utópica":

Ao projeto totalizador da vanguarda, que, no limite, só a utopia redentora pode sustentar, sucede a pluralização de poéticas possíveis. Ao princípio-esperança, voltado

\footnotetext{
${ }^{7}$ KRISTEVA. Monstrueuse intimité, p. 59.

${ }^{8}$ KRISTEVA. Contre la dépression nationale, p. 104.

${ }^{9}$ PEPETELA. Muana Puó, p. 166-7.

${ }^{10}$ Uma tradução literal dos versos citados poderia ser: O que acontece com um sonho sempre adiado?/ Seca/ como uma passa ao sol?/ Ou inflama como uma ferida/ que depois supura?/ (...) Talvez ele apenas desabe,/ como carga muito pesada./ Ou explode?
} 
para o futuro, sucede o princípio-realidade, fundamento ancorado no presente. (...) uma poesia do "outro presente" e da "história plural", que implica uma "crítica do futuro" e de seus paraísos sistemáticos. (...) o presente não conhece senão sínteses provisórias e o único resíduo utópico que nele pode e deve permanecer é a dimensão crítica e dialógica que inere à utopia. ${ }^{11}$

Uma resposta sobre os rumos da utopia pode ser lida em uma obra recente de Pepetela, A montanha da água lilás: fábula para todas as idades. Trata-se, aparentemente, de um livro voltado para o público infantil - ou para aqueles que Harold Bloom denomina "crianças extremamente inteligentes de todas as idades" 12 -, como indicam o título e o estilo da narrativa, baseada na oralidade e voltada para a transmissão de valores sociais e de padrões de comportamento. Entretanto, a utilização da narrativa oral como modelo acaba funcionando como álibi para a criação de uma versão alegórica da história recente da África, mais especificamente de Angola, transformada em montanha-paraíso, dotada de recursos naturais abundantes, mas incapaz de uma organização social que permita a distribuição equânime das riquezas. O resultado é a expulsão desse paraíso e sua destruição, não devido a uma vingança dos deuses, mas pela incapacidade de lidar com a natureza e com o outro.

Na "Apresentação" do livro, o narrador adverte: "Eu só escrevi aquilo que o avô nos contou, não inventei nada", ${ }^{13}$ distanciando-se ironicamente da narrativa. Pepetela incorpora ao texto escrito o modo de circulação das narrativas orais, isto é, a situação original de comunicação direta que legitima a comunicação e de certa forma disfarça o caráter de texto escrito, visando aproximá-lo ao máximo do contexto social que o gerou. Incorpora também o modelo da fábula, situando a ação "no tempo em que os animais falavam" para, através do antropomorfismo, construir uma alegoria clássica que é, ao mesmo tempo retrospectiva e prospectiva. Isto porque, através da história de animais reais (leões, hipopótamos, cobras) ou inventados pelo autor (os lupis e jacalupis), o texto narra a história de Angola no período pós-independência, as oportunidades perdidas e os erros que levaram à situação atual, e, ao mesmo tempo, propõe um projeto para o futuro, que, na verdade, funciona de forma circular, ao apontar para um recomeço, para uma retomada do projeto anterior, com as correções necessárias. Na verdade, a narrativa acaba por funcionar como um balanço (e uma confirmação) do projeto utópico socialista como um todo, independente da sociedade em que ele seja aplicado, já que o modelo da fábula permite uma leitura alegórica mais aberta. Além disso, o narrador afirma na apresentação que, segundo o avô Bento, "a história se passou aqui mesmo, nas serras ao lado, mas pode ser que fosse trazida de qualquer parte de África. Até mesmo do Oriente, onde dizem há muita água lilás". E completa: "Se virmos bem, em muitos lados pode ter uma montanha semelhante", o que pode ser entendido como uma referência aos projetos utópicos fracassados em lugares diversos, no Segundo e no Terceiro Mundo.

\footnotetext{
${ }^{11}$ CAMPOS. Poesia e modernidade: da morte da arte à constelação. O poema pós-utópico, p. 268.

${ }^{12}$ Refiro-me ao título da antologia organizada por Harold Bloom, Stories and Poems for Extremely Intelligent Children of All Ages. New York: Scribner, 2001.

${ }^{13}$ PEPETELA. A montanha da água lilás, p. 11. Note-se que o avô se chama Bento: coincidência ou referência à Dona Benta de Lobato?
} 
A fábula inicia num cenário que evoca uma Idade de Ouro: uma montanha privilegiada pela natureza, habitada por seres que conseguem conviver com suas diferenças e expulsar os animais invasores literalmente no grito, isto é, "lupilando" e "exagera[ndo] na gritaria" ${ }^{14}$ Mas a situação não se resolve com a expulsão dos invasores, pois as diferenças físicas e de comportamento entre os habitantes gradualmente se acentuam, gerando mudanças que resultam em aparências físicas cada vez mais diferentes, acentuadas pela adoção entusiasmada de signos de riqueza: vestimentas e adornos que são mostrados como totalmente ridículos. Além dessa crítica aos desvios do sonho de uma sociedade igualitária devido à ênfase nos sinais externos de riqueza e de hierarquia, expressões da linguagem econômica e política contemporânea estão inseridas ao texto, reforçando a ironia e o estranhamento, bem como conduzindo o leitor (em especial o leitor adulto) a uma leitura política e histórica da fábula. Esse é o caso, por exemplo, das referências à "economia de mercado," 15 às atividades do "serviço secreto," 16 à "paz armada e contra-armada" 17 , entre outras. É importante observar que a narrativa se dá a partir do ponto de vista de dois personagens emblemáticos: o lupi-poeta e o lupi-pensador, que aos poucos vão sendo exilados no alto das árvores, impedidos de participar ativamente das decisões políticas em virtude de suas criticas aos rumos tomados pela sociedade. Ao final da narrativa, os moradores da montanha vivenciam a falência do que se apresenta claramente como um modelo econômico equivocado, baseado na exploração predatória dos recursos naturais, e acabam forçados a emigrar e a trabalhar, em condições humilhantes, para os antigos compradores de seus produtos. Assim, conta o narrador, "O lupi-pensador e o lupi-poeta continuaram na montanha, comendo as frutas das árvores. (...) agora tinham uma vida livre pela montanha, como nos velhos tempos, mas tinham saudades dos outros lupis. Tinham sobretudo pena deles, escravos de si próprios." 18

Em A montanha da água lilás, os intelectuais conseguem uma vitória relativa, embora sejam expulsos da cidade e tenham que se proteger no alto das árvores, de onde observam os acontecimentos. Impossível não se lembrar aqui de Calvino, principalmente depois de evocado por Umberto Eco em seus comentários sobre a conveniência de os intelectuais se imporem um afastamento parcial do engajamento político:

Bem, há um livro de Italo Calvino de que eu gosto muito, chamado O barão nas árvores, que é a história de um aristocrata do século XVIII que decide passar o resto de sua vida no alto de uma árvore sem jamais descer. Mas, ao fazer isso ele ainda assim participa da Revolução Francesa... Ele é uma metáfora, uma alegoria. Há uma maneira de ficar em cima de uma árvore e mudar a vida no chão ${ }^{19}$.

De modo análogo, o lupi-poeta e o lupi-pensador, no alto das árvores, protegidos da violência dos poderosos, ainda podem tentar "mudar a vida no chão", tirando partido de sua posição

\footnotetext{
${ }^{14}$ PEPETELA. A montanha da água lilás, p. 26.

${ }^{15}$ PEPETELA. A montanha da água lilás, p. 89.

${ }^{16}$ PEPETELA. A montanha da água lilás, p. 97.

${ }^{17}$ PEPETELA. A montanha da água lilás, p. 145.

${ }^{18}$ PEPETELA. A montanha da água lilás, p. 162.

${ }^{19}$ ECO. Apocalypse Postponed, p. 8.
} 
privilegiada de distanciamento relativo, tornando-se espectadores conscientes da História, participando ao registrá-la de modo crítico. Daí o conselho do lupi-pensador: "Lupi-poeta, tens que contar tudo isso que passou. Para que os lupis não se esqueçam de seus erros." 20 No entanto, a pergunta final não demonstra certeza na eficácia do ato de narrar ou de rememorar para efetuar transformações radicais. São esses poemas que os mais velhos legaram "às gerações vindouras", porém, a dúvida permanece: "Aprenderão elas com a estória?"21; ou seja, aprenderão elas com a História?

A experiência tem mostrado que não; no entanto, permanece a necessidade de narrar, mantendo viva a "sagrada esperança" cantada por Agostinho Neto. Isto porque essa fábula de Pepetela como que "ignora" o fim melancólico das utopias socialistas ao defender o modelo como sendo ainda válido para a época contemporânea. Assim, A montanha da água lilás consiste numa clara reescrita da grande narrativa da revolução socialista, de forma crítica, mas endossando totalmente um projeto que não suportou o teste da realidade. $\mathrm{O}$ livro pode ser visto, então, como mais um relato nostálgico sobre o fim dos sonhos do século XX, que talvez faça mais sentido quando lido de forma retrospectiva por aqueles que neles acreditaram do que para o aparente público-alvo: as novas gerações. O livro caracteriza-se, assim, pelo que Svetlana Boym denomina "nostalgia restauradora,"22 baseada numa certa recusa de aceitar a experiência da história, num processo de denegação (disavowal) - que leva o sujeito a insistir em dizer: eu sei, mas mesmo assim... - e na saudade do potencial positivo, ainda não explorado, do comunismo ou do socialismo. A dimensão utópica se dirige, assim, mais para o passado do que para o futuro.

Como caracterizar, então, esse discurso que insiste em valorizar a memória, apesar da consciência do provável fracasso da evocação do passado para se modificar a sociedade? $\mathrm{Na}$ minha opinião, uma abordagem possível seria considerar os textos de Pepetela como pertencendo à tradição do discurso melancólico discutido inicialmente por Freud e, posteriormente, por outros pensadores como Walter Benjamin e Julia Kristeva ${ }^{23}$.

Freud desenvolve sua teoria sobre o assunto em "Luto e melancolia", em que apresenta suas idéias sobre o que denomina "trabalho de luto", que poderia ser esquematicamente descrito como um processo em que o indivíduo testa, continuamente, a realidade a fim de estabelecer a perda; em seguida, busca, aos poucos, retirar a emoção do objeto perdido, até se libertar do peso da dor que o perseguiu até então. No caso do melancólico, esse trabalho não resulta na libertação do individuo; ao invés disso, ele se volta para um processo de autocrítica, continuando a sofrer, mas encontrando satisfação na auto-exposição. Sem conseguir assimilar, identificar, ou mesmo se identificar, com o objeto perdido, o melancólico freqüentemente se expressa através da crítica cultural ou social. Ao contrário daqueles tomados pela depressão ou abatidos por um trauma, o melancólico fala: ao adotar o paradigma do homo narrans, reconhece a perda através de um saber mais lúcido sem, no entanto, conseguir completar a operação de desinvestimento da libido, alcançado pelo trabalho do luto.

${ }^{20}$ PEPETELA. A montanha da água lilás, p. 163.

${ }^{21}$ PEPETELA. A montanha da água lilás, p. 163.

${ }^{22}$ BOYM. The Future of Nostalgia, p.xviii.

${ }^{23} \mathrm{Cf}$, entre outros: FREUD, Mourning and melancholy; KRISTEVA. Sol negro: depressão e melancolia; PENSKY. Melancholy Dialectics. 
"Todos os sofrimentos podem ser suportados se os colocamos em uma história ou se contamos uma história sobre eles", observou Isak Dinesen/ Karen Blixen. ${ }^{24}$ Para Pepetela, como para outros intelectuais que passaram pelo processo da descolonização e, mais tarde, pelas decepções com os rumos das sociedades pós-coloniais, "a luta continua", como dizia a palavra de ordem da época revolucionária. Mas trata-se de outro tipo de luta: a luta para expressar, no discurso melancólico da memória, não mais a "sagrada esperança" que inspirou o nascimento das modernas nações africanas, mas o espírito de revolta como rebelião criativa e, apesar de tudo, visionária.

\section{(4)}

\section{ABSTRACT}

Decades after the process of decolonization, contemporary African authors are now trying to criticize the political situation of the new nations and to face the end of the revolutionary utopias. In his fable A montanha da água lilás, Pepetela records Angola's past, points out the errors committed by the postcolonial governments and reaffirms his belief in a remodelled socialist dream.

\section{KEY WORDS}

utopia, African literature, Pepetela.

\section{REFERÊNCIAS BIBLIOGRÁFICAS}

Ashcroft, Bill, et al. The Empire Writes Back: Theory and Practice in Post-colonial Literatures. London: Routledge, 1989.

Boenmer, Elleke. Colonial and Postcolonial Literature. Migrant Metaphors. Oxford: Oxford University Press, 1995.

Boym, Svetlana. The Future of Nostalgia. New York: Basic Books, 2001.

CAmpos, Haroldo de. Poesia e modernidade: da morte da arte à constelação. O poema pósutópico. In: O arco-íris branco: ensaios de literatura e cultura. Rio de Janeiro: Imago, 1997. p. 243-269.

Eco, Umberto. Apocalypse Postponed. Ed. Robert Lumley. Bloomington and Indianapolis: Indiana University Press; London: British Film Institute, 1994.

Freud, Sigmund. Mourning and melancholia. In: Strachey, James (Ed.). The Standard Edition of the Complete Psychological Works of Sigmund Freud, vol. XIV. London: Hogarth, 1957.

JAmEson, Fredric. Third-World Literature in the Era of Multinational Capitalism. Social Text, 15. Theory, Culture, Ideology. p. 65-88, Fall 1986.

Kristeva, Julia. Contre la dépression nationale. Entretien avec Phillipe Petit. Paris: Textuel, 1998.

${ }^{24}$ Citado em KRISTEVA. Crisis of the European Subject, p. 77. Kristeva, por sua vez, cita Hannah Arendt. 
Kristeva, Julia. Crisis of the European Subject. Transl. Susan Fairfield. New York: Other Press, 2000.

KRISTEVA, Julia. "Monstrueuse intimité. (De la littérature comme expérience)", L'Infini 48 (hiver 1994), p. 55-61.

KRIsteva, Julia. Sol negro: depressão e melancolia. Trad. Carlota Gomes. Rio de Janeiro: Rocco, 1989.

Owomoyela, Oyekan (Ed.). A History of Twentieth-Century African Literatures. Lincoln and London: University of Nebraska Press, 1993.

Pensky, Max. Melancholy Dialectics. Walter Benjamin and the Play of Mourning. Amherst: University of Massachusetts Press, 1993.

Pepetela. A geração da utopia. Rio de Janeiro: Nova Fronteira, 2000.

Pepetela. A montanha da água lilás. Fábula para todas as idades. Porto: Dom Quixote, 2000.

Pepetela. Muana Puó. Lisboa: Edições 70, 1978.

Sommer, Doris. Foundational Fictions. The National Romances of Latin America. Berkeley: University of California Press, 1991.

VenÂNCIO, José Carlos. Literatura e poder na África lusófona. Lisboa: Ministério da Educação, Instituto de Cultura e Língua Portuguesa, 1992.

VenÂncio, José Carlos. Literatura versus sociedade. Uma visão antropológica do destino angolano. Lisboa: Veja, 1992. 